\title{
Social Enterprise and Self-rated Health Among Low-Income Individuals in South Korea: A Multilevel Analysis
}

\author{
Hyejin Jung ${ }^{1}$ (D) Changbin $\mathrm{Woo}^{2}$ (1)
}

Accepted: 28 April 2021/Published online: 23 May 2021

(C) The Author(s) 2021

\begin{abstract}
Previous studies have shown that social enterprises can improve the health conditions of socially disadvantaged people through qualitative approaches. As income-related health inequality has grown, the role of social enterprises in addressing this issue has become more significant. This study examined whether social enterprises could positively affect the self-rated health of South Korean low-income residents using multilevel models. The results showed that government-certified social enterprises were associated with positive self-rated health among lowincome residents. On the other hand, preliminary social enterprises with insufficient profitability and weak corporate governance showed mixed results. Based on the empirical results, this study suggests relevant policy implications.
\end{abstract}

Keywords Social enterprise $\cdot$ Self-rated health $\cdot$ Multilevel analysis · South Korea

\section{Introduction}

Social enterprises have often been proposed as an alternative channel for enhancing public health, especially among vulnerable people. Recently, a growing number of

Changbin Woo

changbinwoo@gmail.com

Hyejin Jung

hjung@pusan.ac.kr

1 Pusan National University, 2, Busandaehak-ro 63beon-gil, Geumjeong-gu, Busan 46241, South Korea

2 Kyung Hee University, 26 Kyunghee-daero, Dongdaemungu, Seoul 02447, South Korea studies have suggested that social enterprises can provide various programs, products, and services to populations that are more likely to suffer from health inequalities (Roy \& Hackett, 2017; Roy et al., 2013; Thomson et al., 2006). The use of social enterprises to enhance the public health of socially disadvantaged people is gaining widespread acceptance. Given that the sole efforts of governments can hardly solve the causes and problems of health inequalities, many attentions have been paid to the role of social enterprises (Roy et al., 2013; Thomson et al., 2006).

The results of previous studies on social enterprises' contributions to public health can help describe the mechanisms through which social enterprises benefit socially disadvantaged sections (De Ruysscher et al., 2017; Roy et al., 2014). Except for a few studies (Ferguson \& Xie, 2008; Jang et al., 2018), most research has largely utilized qualitative approaches, including case studies with interviews, to examine the effects of social enterprise on the mental and physical health of socially disadvantaged groups (Bertotti et al., 2012; Farmer et al., 2016; Ferguson, 2007; Ferguson \& Islam, 2008; Ferguson \& Xie, 2008; Munoz et al., 2015). By linking relevant theories (e.g., social capital, capability, and a space of well-being) to empirical cases, several studies have systemically reviewed how social enterprises can enhance public health and wellbeing (Calò et al., 2018; Roy et al., 2013).

However, the extant studies on the relationship between social enterprises and vulnerable social groups' health had some limitations. First, these studies drew largely from a small number of cases and interviews; this led to a simplification of what social enterprises concretely do (Macaulay et al., 2018). Furthermore, previous studies disregarded how local contexts could affect the well-being and subjective health of low-income individuals. It is quite embarrassing that the orientation and the impact of social 
enterprises should be understood in their social and community contexts (Mazzei, 2017; Mendell, 2010). Finally, prior studies were not concerned with the capacities of social enterprises, which directly and indirectly affect their effectiveness in supporting socially vulnerable people.

Therefore, this study attempts to answer the following questions through multilevel models, considering individual characteristics and local contexts simultaneously:

(1) Do social enterprises improve low-income residents' subjective health in local communities? (2) Compared to other social enterprises, are high-capacity social enterprises more beneficial for the subjective health of low-income individuals?

\section{Contribution of Social Enterprises to Well-Being of Low-Income People}

Based on relevant studies, we suggest that social enterprises can enhance the health and well-being of vulnerable social groups by: (1) providing affordable healthcare products and services, (2) increasing health conditions and capabilities, and (3) acting as community "boundary spanners." These three roles are entangled and variously combined.

First, social enterprises provide affordable healthcare goods and services. These needs are often not satisfied by markets and governments (Seelos \& Mair, 2005). In particular, significant unmet healthcare needs have been observed among poor people living in remote areas (Allin et al., 2010). Thus, social enterprises deliver free services or low-cost healthcare services to those at the bottom of the societal pyramid (Prahalad, 2005) and subsistence consumers (Viswanathan \& Rosa, 2007) through governmentpartnered collaborative efforts (Agarwal et al., 2018; Seelos \& Mair, 2005; Weidner et al., 2010). In contrast to the traditional belief that subsistence consumers who face dayto-day life challenges cannot afford to buy healthcare services, the market consisting of such people is growing (Weidner et al., 2010). By identifying the health needs of subsistence or low-income consumers, social enterprises can introduce affordable healthcare products and services for this demographic. During the process, they can create a social impact and generate profits to sustain their businesses (Agarwal et al., 2018).

To serve low-income customers in the health market, social entrepreneurs should be innovative, as they may have to work with several resource constraints (Morais-daSilva et al., 2020; Shaw \& Carter, 2007; Weidner et al., 2010). In this respect, social entrepreneurs can also deliver more affordable, accessible, and acceptable healthcare solutions to low-income individuals (Bhattacharyya et al., 2010). For instance, a study by Vickers et al. (2017) described how social enterprises adopted new or improved existing health services for their communities, especially for vulnerable groups. Social enterprises attempted to meet their communities" healthcare needs with "value for money" strategies. Therefore, the contributions of social enterprises can take several forms such as improvements to current systems, solution creation, and the invention of new approaches for improving health conditions among lowincome individuals (Seelos \& Mair, 2005).

Second, through various programs and services for socially vulnerable groups, social enterprises can offer health interventions to improve mental and physical health (Chan, 2016; Ferguson, 2007). For instance, Ferguson and his colleagues found that social enterprise-based intervention (SEI) models, such as mentoring, job skills training, and clinical service referrals, positively affected the mental health status of homeless youth who participated in such programs (Ferguson, 2007; Ferguson \& Islam, 2008; Ferguson \& Xie, 2008). In addition, recent case studies have also illustrated that participants who involved themselves in the physical activities provided by social enterprises experienced physical recovery or improved physical health (Ferguson \& Islam, 2008; Macaulay et al., 2018; Munoz et al., 2015). In this regard, social enterprises are thus suggested as potential spaces of well-being, where disadvantage people can experience therapeutic landscapes (Farmer et al., 2016; Munoz et al., 2015).

Several studies have employed the capability approach promoted by Sen (1992) and Nussbaum (2000) to discuss how social enterprises can contribute to individual empowerment and realization of well-being (Chan et al., 2017; Munoz et al., 2015; Tanekenov et al., 2018; Weaver, 2018). Based on improvements in their physical and mental health described above, participants were able to obtain relevant skills and qualifications that could increase their employment opportunities. As individuals gain greater access to income, they become more likely to feel selfesteem, empowerment, and social integration, which can positively affect their health and quality of life (Haugh, 2006; Munoz et al., 2015; Roy et al., 2014; Teasdale, 2010).

Finally, social enterprises can help vulnerable people feel a sense of connectedness by acting as boundary spanners (Caló et al., 2019; Farmer et al., 2016). Boundary spanning refers to activities promoting significant transactions with out-group members that can facilitate intergroup contacts and effective intergroup relationships (Richter et al., 2006). Frequent contacts with other groups result in better communication and understanding of the values, cultures, and norms of two or more domains (Kilpatrick et al., 2007). In this vein, social enterprises span the domains of socially excluded people and local community 
to integrate marginalized people into the wider community (Farmer et al., 2016).

Previous studies discerned that social enterprises act as boundary spanners by linking socially disconnected people to supportive environments in which social capital and trust can be created (Caló et al., 2019). For instance, a recent study of Caló et al. (2019) reported that beneficiaries who had experienced chronic hospitalization and illness experienced "normality" and felt social reconnection, which can foster well-being, through the healthcare service provided by a social enterprise. In a similar approach, Barraket and Archer (2010) described that community-based social enterprises promoted social inclusion through economic participation, social participation, civic participation, and access to various local and non-local services that could increase the well-being of community residents. Farmer et al. (2016) also suggested that several members and volunteers working for social enterprises play significant roles in connecting socially vulnerable people to community life.

Hence, it is expected that social enterprises can contribute to the health and well-being of socially vulnerable people in local communities through various channels. However, it is notable that these mechanisms are not mutually exclusive, which implies that the supply of affordable healthcare services, building capability to prevent social isolation in local communities, and boundary spanning during transactions and communication directed at increasing social trust are closely related.

\section{Two Types of Social Enterprises in South Korea}

It should be noted that the effectiveness of social enterprises in improving the health conditions of low-income residents can largely be influenced by their capacity to promote their missions (Caló et al., 2019; Diochon \& Anderson, 2009). It means that not all social enterprises trying to increase the well-being of socially vulnerable people are effective. Access to available financial and human resources can be a critical factor affecting the performance of social enterprises (Caló et al.,, 2019). To evaluate the resources and capacities of social enterprises, this study primarily explores two different types of social enterprises in South Korea in terms of a certification system managed by the Korea Social Enterprise Promotion Agency and government ministries, while there exist a variety of models of social enterprise in the country (Bidet et al., 2018).

The first type of social enterprises is certified social enterprises, referring to entities that are registered as formal social enterprises with legal and relevant requirements based on the Social Enterprise Promotion Act enacted in
2006. The act clarifies that certified social enterprises should fulfil several administrative and financial conditions, such as sufficient profit making, employment of disadvantaged people, and a participatory decision-making process. Once they become certified social enterprises, they are eligible to receive financial and institutional support, such as subsidies for employees' salaries, public procurements, R\&D investments for innovation, tax exemptions, and subsidies for social insurance fees.

The second type is preliminary social enterprises, indicating informal social enterprises as they do not meet the specific legal requirements mentioned above. The differences between preliminary and certified social enterprises can be found in the process of business operations and financial support received from the government. Preliminary social enterprises are not sufficiently profitable to enable sustained operations, and lack participatory decision-making processes with interested groups, such as stakeholders and consumers. Hence, they are excluded from tax exemptions and subsidies for social insurance fees though other benefits and support provided to them are akin to those offered to certified enterprises. Therefore, it is obvious that preliminary social enterprises have lower capacities to generate sufficient profits and less available financial resources from the government compared to certified social enterprises.

Though the primary purpose of this study is not to explore the effects of financial support received from the government, it is noteworthy that certified social enterprises with abundant financial resources from their business activities and government are likely to achieve their social missions. For instance, recent studies illustrated that government funding and subsidy for certified social enterprises are positively associated with their social performance, such as employment of disadvantaged people and investment in community development (Choi et al., 2020; Kim \& Moon, 2017). These empirical findings can be understood by the argument that institutionally supportive frameworks and financial support enable social enterprises to promote social values because these favorable environments can protect them from pure market risks (Defourny \& Nyssens, 2012).

To conclude, we posit that certified social enterprises with higher capacity are more likely to respond to the unmet needs of low-income people than preliminary social enterprises. Certified social enterprises have more financial resources at their disposal from their sufficient profitability and government support, and a more desirable decisionmaking process with their varied stakeholders. Despite the concern that grants and subsidies from governments may lead to weak autonomy, the available resources of social enterprises largely affect the extent of finding and addressing the needs of socially disadvantaged people. In 
addition, participatory decision-making processes can help make better decisions for socially vulnerable people in local communities.

\section{Data and Methodology}

\section{Data}

The data used in the analysis were collected from three independent sources. For the individual level, we used data from the 2017 Korean Community Health Survey (KCHS), which was conducted through collaborative processes among the Centers for Disease Control and Prevention, various universities, and local community health centers. This survey has been conducted annually since 2008 with the aim of collecting standardized raw data that can be used while designing public health policies. As of 2017, the survey had covered 17 provinces and 254 cities and relevant entities across the nation with 228,381 samples.

Defining low-income residents is critical since how lowincome residents are measured affects the estimation. To prevent arbitrary measurement of low-income people, the annual standard median income of the country, which has been adjusted and reported by the central government since 1973, was utilized (Ministry of Health \& Welfare, 2016). Based on the annual report, we defined low-income individuals as those who earned less than $50 \%$ of the monthly median income, which is a popular and practical way to define low-income people (Spicker, 2012). As the median income for one person per month was about 1449 USD $(1,652,931 \mathrm{KRW})$ in 2017 , we set the cut-off value for lowincome residents at approximately 724 USD (826,466 $\mathrm{KRW}$ ). Among the whole sample, it was found that lowincome individuals who earned less than the cut-off were 45,811 and accounted for $20.06 \%$ of the whole sample, corresponding to the lowest income quintile. Finally, we used 44,026 samples after excluding the missing data.

At the local level, the number of social enterprises and control variables, which are explained below, were obtained from the Korea Social Enterprise Promotion Agency and the Statistics Korea, respectively.

\section{Data Measurement}

In order to obtain robust results, we employed two dependent variables. Participants' self-rated health (SRH) was measured considering their answer to the question: "Overall, how do you feel about your health?" On the one hand, this study employed a five-point Likert scale for a multilevel ordered logistic regression model, ranging from 1 to 5 ( 1 = "very poor," 2 = "poor," $3=$ "fair," $4=$ "good," and 5 = "very good"). On the other hand,
SRH was measured using a dummy variable for a multilevel logistic regression, dichotomized into "good" (responses 3, 4, or 5) and "poor" (responses 1 or 2) to be consistent with previous studies (Meng \& Chen, 2014).

Our main independent variable was the number of social enterprises. It is notable that we included two types of social enterprises, certified and preliminary, due to their different characteristics as described in the previous section. For this reason, we calculated the number of certified and preliminary social enterprises divided by the number of for-profit firms per 100,000 inhabitants as of 2017.

This study also employed multiple control variables, which can have different effects on the SRH of low-income individuals. On the one hand, at the individual level, we included several demographic and socioeconomic variables, such as age, gender, income, education, marital status, employment, trust, and friendship based on previous studies (Baron-Epel \& Kaplan, 2001; Deeming, 2013; Fassio et al., 2013; Franzini \& Fernandez-Esquer, 2006; Meng \& Chen, 2014; Szwarcwald et al., 2005; Van der Horst \& Coffé, 2012). On the other hand, at the local level, we considered several variables, including density, the number of doctors, and the welfare budgets of local governments following the extant studies illustrating the impact of local context on residents' subjective health (Fassio et al., 2013; Forsyth et al., 2007; Kim, 2011; Veenhoven, 2000).

Specific measurements of variables used in the analyses are presented in Table 1.

\section{Analytical Method}

Although SRH has been researched at the individual level, it is desirable to utilize a multilevel analysis to examine social enterprises as a contextual factor for low-income individuals' subjective health. The use of a multilevel framework can allow for variations in SRH to be determined by individual factors and local factors simultaneously (Murayama et al., 2012). Furthermore, multilevel analysis can provide much richer data by analyzing the extent of the relationship between local-level differences and SRH (Habibov \& Afandi, 2011).

Therefore, we analyzed the relationship between social enterprises and low-income residents' SRH using multilevel logistic regression and multilevel ordered logistic regression with the following models. The level 1 model covered individual variables, whereas the level 2 model dealt with local attributes. Let $\operatorname{Pr}_{i j}$ refer to the probability that low-income residents, the $i$ th individual in $j$ th city and any equivalent entities, evaluate their SRH among the categories. 
Table 1 Description of variables

\begin{tabular}{|c|c|}
\hline Variables & Measurement \\
\hline \multicolumn{2}{|l|}{ Dependent variable } \\
\hline Self-rated health & $\begin{array}{l}1-5 \text { Likert scale: } 1=\text { Very poor; } 2=\text { Poor; } 3=\text { Fair; } 4=\text { Good; and } 5=\text { Very good } \\
\text { Dummy variable: } 1=\text { Good; and } 0=\text { Poor }\end{array}$ \\
\hline \multicolumn{2}{|l|}{ Independent variable } \\
\hline Social enterprise & Number of social enterprises/(number of for-profit firms/100,000 inhabitants) \\
\hline \multicolumn{2}{|l|}{ Control variable } \\
\hline \multicolumn{2}{|l|}{ Individual level } \\
\hline Age & 2017-the year of birth \\
\hline Sex & $1=$ male; and $0=$ Female \\
\hline Income & $\begin{array}{l}1 \text { = less than approximately } 500 \text { US dollars; and } 0=\text { more than approximately } 500 \text { US } \\
\text { dollars }\end{array}$ \\
\hline Education & $\begin{array}{l}1=\text { lower secondary school and below; } 2=\text { upper secondary school; } 3=\text { undergraduate; } \\
\text { and } 4=\text { graduate and above }\end{array}$ \\
\hline Marital status & $1=$ married; and $0=$ otherwise \\
\hline Employment & $1=$ employed; and $0=$ otherwise \\
\hline Trust & $1=$ trust respondents' neighborhoods; and $0=$ otherwise \\
\hline Meeting with friends & $\begin{array}{l}1=\text { less than once a month; } 2=\text { once a month; } 3=\text { two to three times a month; } 4=\text { once a } \\
\text { week; } 5=\text { two to three times a week; and } 6=\text { more than four times a week }\end{array}$ \\
\hline \multicolumn{2}{|l|}{ Local level } \\
\hline Density & Ln (number of people per kilometer) \\
\hline Doctor & Number of doctors/(residents /1000 inhabitants) \\
\hline Welfare budget & Percentage of local governments' budget for welfare \\
\hline
\end{tabular}

SRH is initially a binary decision between $Y_{i j}=1$ denoting good $\mathrm{SRH}$ and $Y_{i j}=0$ denoting poor SRH for the multilevel logistic model.

$$
\begin{aligned}
\operatorname{logit}\left(\operatorname{Pr}\left(Y_{i j}=1\right)\right)= & \alpha_{0}+\alpha_{0 j}+\alpha_{1} x_{1 i j}++\alpha_{k} x_{k i j}+\beta_{1} z_{1 j} \\
& +\beta_{m} z_{m j}
\end{aligned}
$$

Let $x_{1 i j}$ through $x_{k i j}$ refer to $k$ predictor variables at the individual level (i.e., age, gender, income, education, marital status, employment, trust, and friendship). Let $z_{1 j}$ through $z_{m j}$ refer to the $m$ predictor variables at the local level (i.e., social enterprises, population density, number of doctors, and welfare budget).

Then, the dependent variable has five categories (very poor, poor, fair, good, and very good) as a set of cut-points on the link for each individual. A link transformation of $Y_{i j}^{(s)}(s=1,2, \ldots, 5)$ corresponds to sequential positions on the sample $\left(\alpha_{i j}^{(1)}, \alpha_{i j}^{(2)} \alpha_{i j}^{(3)}, \alpha_{i j}^{(4)},+\infty\right)$ for the multilevel ordered logistic model:

$$
\begin{aligned}
\operatorname{logit}\left(\operatorname{Pr}\left(Y_{i j}^{(s)}\right)\right)= & \alpha_{0}+\alpha_{0 j}+\alpha_{1} x_{i j}+\cdots+\alpha_{k} x_{k i j}+\beta_{1} z_{1 j} \\
& +\beta_{m} z_{m j} \\
(s=1,2,3,4) &
\end{aligned}
$$

In the models, the effect of each independent variable was assumed to be a fixed parameter that had to be estimated. However, there was a random intercept: the large proportion of total variance in SRH results from city level differences. All independent variables were centered on their means, as centered data can increase the interpretability of intercept terms (Kreft et al., 1995).

The coefficients of all the models were converted into odds ratios (ORs) with $95 \%$ credible intervals (CIs). To explore the impact of the local level context and the model fit, we estimated intra-class correlation (ICC) for the multilevel logistic regression and multilevel ordered logistic regression. The analyses were conducted using the statistical software package STATA 15.0 with the melogit command for the multilevel logistic regression and the meologit command for multilevel ordered logistics regression. 


\section{Results}

\section{The Attributes of Respondents}

Table 2 presents the descriptive statistics of the selected variables. In the case of the individual level variables, there were distinctive features regarding the demographic and socio-economic variables. The average age was 70.1, which implied that elderly people made up a significant proportion of the low-income group, and respondents aged above 60 years formed about $84.4 \%$ of the sample. Regarding gender differences, females formed $63.8 \%$ of the sample. In addition, almost $62.9 \%$ of respondents earned less than 500 US dollars per month, which could be explained by the large proportion of elderly people in the sample. About $79.5 \%$ of respondents selected lower secondary school as their level of education. With regard to employment, $62.1 \%$ of the respondents did not have jobs

Table 2 Descriptive statistics

\begin{tabular}{|c|c|c|c|c|}
\hline Variable & Mean & SD & Number & Percentage \\
\hline \multicolumn{5}{|l|}{ Individual level $(N=44,026)$} \\
\hline Subjective health & 2.548 & 0.980 & & \\
\hline Good subjective health & & & 22,168 & $50.35 \%$ \\
\hline Poor subjective health & & & 21,858 & $49.65 \%$ \\
\hline Age & 70.063 & 13.267 & & \\
\hline \multicolumn{5}{|l|}{ Sex } \\
\hline Male & & & 15,947 & $36.22 \%$ \\
\hline Female & & & 28,079 & $63.78 \%$ \\
\hline \multicolumn{5}{|l|}{ Income } \\
\hline Less than $\$ 500$ (per month) & & & 27,688 & $62.89 \%$ \\
\hline More than $\$ 500$ (per month) & & & 16,338 & $37.11 \%$ \\
\hline \multicolumn{5}{|l|}{ Education } \\
\hline Lower secondary school & & & 35,020 & $79.54 \%$ \\
\hline Upper secondary school & & & 5,993 & $13.61 \%$ \\
\hline Undergraduate & & & 2,772 & $6.30 \%$ \\
\hline Graduate & & & 241 & $0.55 \%$ \\
\hline \multicolumn{5}{|l|}{ Marital status } \\
\hline Married & & & 21,299 & $49.51 \%$ \\
\hline Otherwise & & & 22,227 & $50.49 \%$ \\
\hline \multicolumn{5}{|l|}{ Employment } \\
\hline Employed & & & 16,654 & $37.83 \%$ \\
\hline Unemployed & & & 27,372 & $62.17 \%$ \\
\hline \multicolumn{5}{|l|}{ Trust } \\
\hline Yes & & & 34,647 & $78.67 \%$ \\
\hline No & & & 9.389 & $21.33 \%$ \\
\hline \multicolumn{5}{|l|}{ Meetings with friends } \\
\hline Less than once a month & & & 15,484 & $35.17 \%$ \\
\hline Once a month & & & 4446 & $10.10 \%$ \\
\hline Two to three times a month & & & 3643 & $8.27 \%$ \\
\hline Once a week & & & 3047 & $6.92 \%$ \\
\hline Two to three times a week & & & 5440 & $12.36 \%$ \\
\hline More than four times a week & & & 11,966 & $27.18 \%$ \\
\hline \multicolumn{5}{|l|}{ Local level $(N=254)$} \\
\hline \multicolumn{5}{|l|}{ Social enterprises } \\
\hline Certified & 1.030 & 1.141 & & \\
\hline Preliminary & 1.336 & 2.169 & & \\
\hline Density & 5.614 & 1.938 & & \\
\hline Doctor & 2.477 & 2.126 & & \\
\hline Welfare budget & 0.247 & 0.124 & & \\
\hline
\end{tabular}


for income. Thus, low-income respondents tended to be elderly, females, less educated, and unemployed.

Figure 1 illustrates the distribution of SRH among the respondents. Respondents who answered with "poor" formed the largest portion $(35.1 \%)$, followed by those who evaluated SRH to be "fair" (33.3\%). The percentages of respondents who reported their SRH as being "very poor" and "good" had similar percentages, reaching about $15 \%$ each. The percentage of respondents who answered "very good" formed about $2 \%$ of the whole sample.

\section{The Results of Multilevel Logistic Regression}

Table 3 shows the estimation results obtained from the multilevel logistic regression. We utilized a series of four models: Model 1 was a null model without any explanatory variables, which served as a benchmark for the size of the local-level difference in all the models. Model 2 included the individual-level demographic and socio-economic variables without any local level variables. Models 3 and 4 added social enterprises and local-level variables to the individual-level model. Models 3 and 4 included certified and preliminary social enterprises, respectively. These two models allowed us to investigate whether social enterprises could affect low-income individuals' SRH and whether this relationship was affected by the type of social enterprise after controlling for all individual and local variables.

In Model 1, a 1.5\% variance was observed in low-income individuals' subjective health at the local level. After we added individual variables and local-level confounders, the ICC decreased, as shown in Models 2-4. In addition, the values of log-likelihood decreased as we added variables to Model 1. This indicates that Models 3-4 had a better fit compared to Model 2 in accordance with the principle of "the smaller the better" (Rathmann et al., 2015).

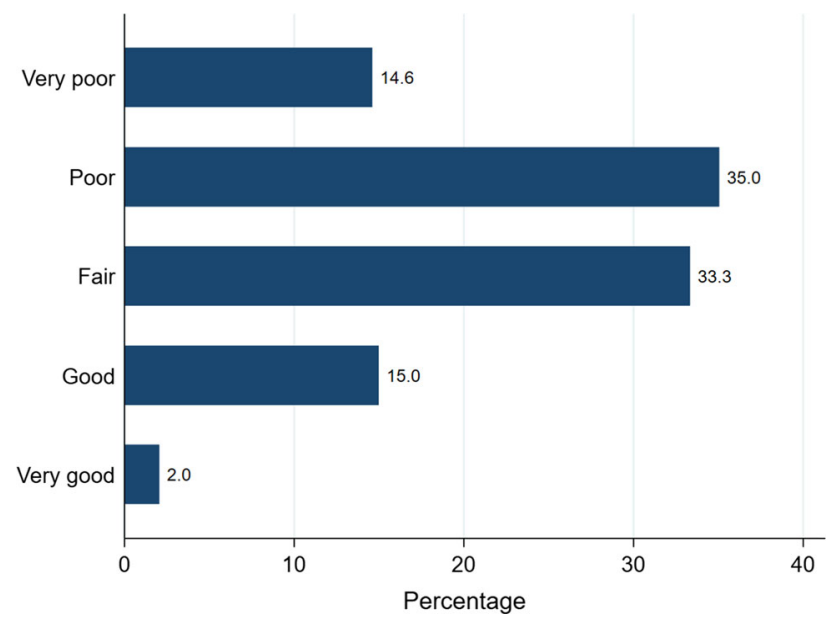

Fig. 1 Proportion of SRH among low-income respondents
Looking at the estimates for certified social enterprises in Model 3, which consisted of individual- and local-level compounds, the analysis results indicated that certified social enterprises were positively related with SRH $(\mathrm{OR}=1.02, p<0.05)$. However, statistical significance was removed in the case of preliminary social enterprises in Model 4. Therefore, it could be inferred that only government-certified social enterprises can improve low-income individuals' SRH, whereas preliminary social enterprises are not strongly associated with low-income individuals' SRH.

\section{The Results of Multilevel Ordered Logistic Regression}

To obtain robust results with regard to the relationship between social enterprises and low-income respondents' SRH, we analyzed multilevel ordered logistic regressions, as presented in Table 4. Similar to Table 3, Model 5 was an empty model, and Model 6 included individual-level variables. Models 7-8 added two types of social enterprises and local-level variables into Model 6. We summarized the ICC values, which were obtained from different models, to confirm whether the application of multilevel analysis was appropriate. As shown, the results of the ICC in Models 7-8 decreased compared to Model 6; this indicated that a multilevel analysis was preferable to a single level analysis.

In Models 7-8, the estimates for the social enterprises showed that both the certified and the preliminary social enterprises could improve SRH, regardless of government certification. Though the odds-ratio of preliminary social enterprises $(\mathrm{OR}=1.01, p<0.01)$ was lower than that of certified social enterprises $(\mathrm{OR}=1.03, p<0.01)$, the results implied that preliminary enterprises also enhanced low-income individuals' SRH.

Excluding the statistical differences of social enterprises, the overall individual- and local-level variables showed extremely similar results in Models 2-5 and 6-8. Figure 2 shows the coefficients obtained from the multilevel logistic regression and multilevel ordered logistic regression. Among the individual levels, all individual variables were positively related with the SRH of lowincome individuals, and age was the only exception to this trend. At the local level, population density was positively associated with subjective health, while the percentage of welfare budget was not statistically significant though it was positive. In contrast, the number of doctors was negatively associated with the SRH of low-income groups.

We more specifically discuss the results of control variables as follows. At the individual level, age was found to be negatively associated with SRH even though the relationship between age and SRH can be biased by the 
Table 3 Multilevel logistic regression estimates (odds ratios and 95\% confidence intervals) and variance components of good health status ( $N=44,026$ individuals nested within $N=254$ cities and equivalent entities)

\begin{tabular}{|c|c|c|c|c|}
\hline Variable & Model 1 & Model 2 & $\begin{array}{l}\text { Model } 3 \\
\text { Certified SEs }\end{array}$ & $\begin{array}{l}\text { Model } 4 \\
\text { Preliminary SEs }\end{array}$ \\
\hline \multicolumn{5}{|l|}{ Fixed effects } \\
\hline \multicolumn{5}{|l|}{ Individual level } \\
\hline Age & & $0.97(0.96-0.97)^{* * *}$ & $0.97(0.96-0.97) * * *$ & $0.97(0.96-0.97)^{* * *}$ \\
\hline Sex (ref. women) & & $1.25(1.19-1.30)^{* * *}$ & $1.25(1.19-1.30)^{* * *}$ & $1.25(1.19-1.30)^{* * *}$ \\
\hline Income & & $1.23(1.17-1.28)^{* * *}$ & $1.21(1.16-1.27)^{* * *}$ & $1.21(1.44-1.58)^{* * *}$ \\
\hline Education & & $1.52(1.46-1.59)^{* * *}$ & $1.51(1.44-1.58)^{* * *}$ & $1.51(1.44-1.58)^{* * *}$ \\
\hline Marital status & & $1.11(1.06-1.16)^{* * * *}$ & $1.12(1.07-1.17)^{* * *}$ & $1.12(1.07-1.17)^{* * *}$ \\
\hline Employment & & $1.95(1.87-2.04)^{* * *}$ & $1.99(1.90-2.08)^{* * *}$ & $1.99(1.90-2.08)^{* * *}$ \\
\hline Trust & & $1.26(1.19-1.32)^{* * *}$ & $1.29(1.22-1.36)^{* * *}$ & $1.29(1.22-1.36)^{* * *}$ \\
\hline Meetings with friends & & $1.10(1.09-1.11)^{* * *}$ & $1.10(1.01-1.09)^{* * *}$ & $1.10(1.01-1.09)^{* * *}$ \\
\hline \multicolumn{5}{|l|}{ Local level } \\
\hline Social enterprise & & & $1.02(1.00-1.05)^{*}$ & $1.00(0.99-1.08)$ \\
\hline Density & & & $1.05(1.01-1.09)^{* *}$ & $1.04(1.01-1.08)^{*}$ \\
\hline Doctor & & & $0.98(0.96-0.99)^{*}$ & $0.98(0.96-0.99)^{*}$ \\
\hline Welfare budget & & & $1.36(0.80-2.31)$ & $1.42(0.83-2.44)$ \\
\hline \multicolumn{5}{|l|}{ Random effects } \\
\hline Local-level variance & 0.050 & 0.044 & 0.028 & 0.029 \\
\hline Standards error & 0.007 & 0.006 & 0.005 & 0.005 \\
\hline Log-likelihood & $-30,405.207$ & $-27,797.839$ & $-27,769.141$ & $-27,770.579$ \\
\hline Intra-class correlation & 0.015 & 0.013 & 0.008 & 0.009 \\
\hline
\end{tabular}

$* p<0.05 ; * * p<0.01 ; * * * p<0.001$. All independent variables are entered as centered variables

self-reporting of conditions (Baron-Epel \& Kaplan, 2001). Like the extant studies reporting a distinction between the sexes (Szwarcwald et al., 2005), the results of this study indicated that men appeared to have better SRH than women. Though the sample used in our analysis was limited to the responses of low-income individuals, a relatively higher income was positively associated respondents' SRH, which is consistent with previous studies (Fassio et al., 2013). The result showing that a lower education level can lead to poor SRH was also similar to previous studies (Deeming, 2013; Franzini \& Fernandez-Esquer, 2006). With regard to marital status, married people were more likely to have favorable SRH compared to others in the marital status sub-group, as married people tended to avoid isolation. This finding was similar to that of previous studies (Deeming, 2013; Fassio et al., 2013; Van der Horst \& Coffé, 2012). Turning to employment status, those who were employed were more likely to have better SRH compared to those who were unemployed, as they had the capability to improve their health conditions because of the income they earned from paid work (Deeming, 2013; Franzini \& Fernandez-Esquer, 2006). In addition, trust and friendship networks also indicated that these interpersonal relationships could help people experience a sense of receiving and providing social support and, thus, build better health (Habibov \& Afandi, 2011; Van der Horst \& Coffé, 2012).

At the local level, the positive relationship between population density and SRH can be explained by the following trend: densely populated areas tend to benefit lowincome individuals because they can increase their accessibility to public transport and employment opportunities (Kim, 2011). In addition, living in an area with higher density could accelerate physical activity and overall working, which, in turn, could positively affect SRH (Forsyth et al., 2007). Meanwhile, the number of doctors was negatively associated with low-income individuals' $\mathrm{SRH}$, which is somewhat puzzling. Finally, like the previous study, the percentage of local government's welfare budget did not improve the SRH of low-income residents (Veenhoven, 2000).

\section{Discussion and Conclusion}

It has been suggested that social enterprises can enhance health and well-being (Munoz et al., 2015; Roy \& Hackett, 2017; Roy et al., 2013, 2014). However, previous studies dealing with the role of social enterprises in improving 
Table 4 Multilevel ordered logistic regression estimates (odds ratios and 95\% confidence intervals) and variance components of good health status, $N=44,026$ individuals nested within $N=254$ cities and equivalent entities

\begin{tabular}{|c|c|c|c|c|}
\hline Variable & Model 5 & Model 6 & $\begin{array}{l}\text { Model } 7 \\
\text { Certified SEs }\end{array}$ & $\begin{array}{l}\text { Model } 8 \\
\text { Preliminary SEs }\end{array}$ \\
\hline \multicolumn{5}{|l|}{ Fixed effects } \\
\hline \multicolumn{5}{|l|}{ Individual level } \\
\hline Age & & $0.97(0.97-0.98)^{* * *}$ & $0.97(0.97-0.98)^{* * *}$ & $0.97(0.97-0.98)^{* * *}$ \\
\hline Sex (ref. women) & & $1.26(1.21-1.31)^{* * *}$ & $1.26(1.21-1.31)^{* * *}$ & $1.26(1.21-1.31)^{* * *}$ \\
\hline Income & & $1.22(1.17-1.27)^{* * *}$ & $1.21(1.16-1.25)^{* * *}$ & $1.21(1.16-1.25)^{* * * *}$ \\
\hline Education & & $1.52(1.47-1.58)^{* * *}$ & $1.52(1.46-1.57)^{* * *}$ & $1.52(1.46-1.57)^{* * *}$ \\
\hline Marital status & & $1.07(1.03-1.12)^{* * *}$ & $1.08(1.04-1.12)^{* * *}$ & $1.08(1.04-1.12)^{* * *}$ \\
\hline Employment & & $1.92(1.84-1.99)^{* * *}$ & $1.94(1.87-2.02)^{* * *}$ & $1.94(1.87-2.02)^{* * * *}$ \\
\hline Trust & & $1.29(1.23-1.35)^{* * *}$ & $1.31(1.25-1.37)^{* * *}$ & $1.31(1.25-1.37)^{* * *}$ \\
\hline Friend & & $1.11(1.10-1.12)^{* * *}$ & $1.11(1.10-1.12)^{* * *}$ & $1.11(1.10-1.12)^{* * * *}$ \\
\hline \multicolumn{5}{|l|}{ Local level } \\
\hline Social enterprise & & & $1.03(1.00-1.06)^{* *}$ & $1.01(1.00-1.04)^{* *}$ \\
\hline Density & & & $1.05(1.01-1.09)^{* *}$ & $1.04(1.01-1.08)^{*}$ \\
\hline Doctor & & & $0.98(0.97-1.00)^{*}$ & $0.98(0.97-1.00)^{*}$ \\
\hline Welfare & & & $1.17(0.71-1.90)$ & $1.42(0.83-2.44)$ \\
\hline \multicolumn{5}{|l|}{ Random effects } \\
\hline Local level variance & 0.044 & 0.038 & 0.029 & 0.029 \\
\hline Standards error & 0.006 & 0.005 & 0.004 & 0.004 \\
\hline Log-likelihood & $-60,567.636$ & $-57,212.937$ & $-57,191.203$ & $-57,191.914$ \\
\hline ICC & 0.013 & 0.011 & 0.008 & 0.008 \\
\hline
\end{tabular}

$* p<0.05 ; * * p<0.01 ; * * p<0.001$. All independent variables are entered as centered variables. Cut points are excluded from the output

Fig. 2 Coefficients obtained from the multilevel logistic and the multilevel ordered logistic regressions. Note: Reference lines were added to show whether the coefficients were significantly different from zero



physical and mental health conditions have heavily relied on qualitative approaches. Whereas the various channels explaining how social enterprises contribute to the health of socially vulnerable people have been suggested, studies tackling this topic with empirical data are still sparse (Ferguson \& Xie, 2008; Jang et al., 2018). 
Given the paucity of quantitative research on social enterprises, the results obtained from our multilevel analyses reveal the positive effect of social enterprises, particularly the certified ones, on the SRH of low-income individuals. These findings corroborate the argument from illustrative cases demonstrating that social enterprises can enhance the SRH of socially vulnerable people. Furthermore, these results are in line with previous studies illustrating that certified social enterprises can accomplish various social values and performances in the country (Choi et al., 2020; Kim \& Moon, 2017).

The positive relationship between certified social enterprises and the SRH of low-income residents can be explained by two channels. First, it can be interpreted that certified social enterprises can deliver various affordable products and services to low-income individuals, which would directly and indirectly affect SHR (Prahalad, 2005; Vickers et al., 2017). The results indicate the important role of social enterprises in terms of health service delivery specially to low-income people, whereas the welfare budgets in the government sector showed an insignificant estimate. In turn, as reported by previous studies, certified social enterprises can recognize the needs of low-income residents who are dissatisfied by the market and their local government (Allin et al., 2010).

More importantly, during the transactions between social enterprises and low-income residents, certified social enterprises act as boundary spanners enhancing the SHR of low-income individuals (Caló et al., 2019; Farmer et al., 2016). This interpretation seems to be persuasive when one remembers the features of low-income respondents: the average age of respondents is more than 70 years, and more than one third of respondents usually meet their friends less than once a month. As such, a large portion of low-income residents are likely to suffer from irregular social interactions and isolation that can negatively affect their SRH and well-being. While the people face limited opportunities for social interaction, communication and interaction with social enterprises make the low-income residents feel socially connected.

Meanwhile, the relationships for preliminary social enterprises were not clear, as the statistical significance obtained from two different analyses were mixed. The insignificant estimate of preliminary social enterprises in the multilevel logistic regression could be because they do not possess sufficient capacity to recognize or meet the social needs of low-income residents in local communities. This lack of capacity of preliminary social enterprises can be due to their insufficient resources (i.e., financial and human resources) and limited involvement of relevant participants in strategic decisions for socially vulnerable people (Caló et al., 2019; Diochon \& Anderson, 2009). The results illustrate that certified social enterprises with more financial resources and desirable decision-making processes are more effective than preliminary social enterprises in achieving the social mission of enhancing the health conditions of low-income individuals.

Based on these findings, this study draws the following policy implications. First, practitioners in the public sector are suggested to co-design welfare services with social enterprises to understand and reflect the needs of low-income people. As social enterprises communicate and interact with socially vulnerable residents, they can share their opinions derived from boundary spanning activities with practitioners when goods and services are designed. Given that the disparities in healthcare would further enlarge, the information and ideas of social enterprises about the potential needs of low-income people can be utilized in the development of welfare services. We also recommend providing relevant platforms for facilitating on- and off-line mentoring services between certified social enterprises and other social economy organizations, such as preliminary social enterprises, social cooperatives, and community enterprises. The voluntary interactions and communication among various social economy organizations will facilitate the exchange of essential know-how and knowledge that can enhance their abilities to sustain their social missions.

Despite the findings and implications of the current study, it has some limitations. First, it is necessary to consider the effect of income levels while comparing the effects of social enterprises on SRH. Although this study focused on low-income individuals, it is plausible that social enterprises may positively affect middle- and highincome individuals' subjective health. Second, although we included several local confounders, other variables, such as local crime rate (Hanslmaier, 2013) and the level of income inequality (Kelley \& Evans, 2017), could also affect SRH. However, as data are not available at the city-level and for other equivalent entities in the country, it is suggested that relevant local variables should be considered in future studies. Third, although we interpreted social enterprises to be positively associated with SRH among low-income individuals, it does not mean that the relationship between them is causal. A mixed approach combining both qualitative and quantitative methodologies could shed light on the causal relationship between social enterprise and SRH among low-income individuals. Finally, the study results may not be applicable to other countries with different institutions and contextual environments. Comparative studies examining the role of social enterprises in influencing residents' health at the local level would be helpful to explore further the association between social enterprises and residents' SRH. Future studies should bear in mind the limitations described above, and seek to further 
clarify the role of social enterprises in improving the health conditions of low-income people.

Acknowledgements This work was supported by the Ministry of Education of the Republic of Korea and the National Research Foundation of Korea under Grant (NRF-2018S1A3A2075117).

Author Contributions All authors contributed to the study conception and design. The first draft of the manuscript was written by Dr. $\mathrm{HJ}$, and Dr. CW commented on previous versions of the manuscript. All authors read and approved the final manuscript.

\section{Declaration}

Conflict of interest The authors report no potential conflict of interest.

Open Access This article is licensed under a Creative Commons Attribution 4.0 International License, which permits use, sharing, adaptation, distribution and reproduction in any medium or format, as long as you give appropriate credit to the original author(s) and the source, provide a link to the Creative Commons licence, and indicate if changes were made. The images or other third party material in this article are included in the article's Creative Commons licence, unless indicated otherwise in a credit line to the material. If material is not included in the article's Creative Commons licence and your intended use is not permitted by statutory regulation or exceeds the permitted use, you will need to obtain permission directly from the copyright holder. To view a copy of this licence, visit http://creativecommons. org/licenses/by/4.0/.

\section{References}

Agarwal, N., Chakrabarti, R., Brem, A., \& Bocken, N. (2018). Market driving at bottom of the pyramid (BoP): An analysis of social enterprises from the healthcare sector. Journal of Business Research, 86, 234-244.

Allin, S., Grignon, M., \& Le Grand, J. (2010). Subjective unmet need and utilization of health care services in Canada: What are the equity implications? Social Science \& Medicine, 70(3), 465-472.

Baron-Epel, O., \& Kaplan, G. (2001). General subjective health status or age-related subjective health status: Does it make a difference? Social Science \& Medicine, 53(10), 1373-1381.

Barraket, J., \& Archer, V. (2010). Social inclusion through community enterprise?: Examining the available evidence. Third Sector Review, 16(1), 13-28.

Bertotti, M., Harden, A., Renton, A., \& Sheridan, K. (2012). The contribution of a social enterprise to the building of social capital in a disadvantaged urban area of London. Community Development Journal, 47(2), 168-183.

Bhattacharyya, O., Khor, S., McGahan, A., Dunne, D., Daar, A. S., \& Singer, P. A. (2010). Innovative health service delivery models in low and middle income countries-what can we learn from the private sector? Health Research Policy and Systems, 8(1), 1-11.

Bidet, E., Eum, H., \& Ryu, J. (2018). Diversity of social enterprise models in South Korea. VOLUNTAS: International Journal of Voluntary and Nonprofit Organizations, 29(6), 1261-1273.

Caló, F., Roy, M. J., Donaldson, C., Teasdale, S., \& Baglioni, S. (2019). Exploring the contribution of social enterprise to health and social care: A realist evaluation. Social Science \& Medicine, $222,154-161$

Calò, F., Teasdale, S., Donaldson, C., Roy, M. J., \& Baglioni, S. (2018). Collaborator or competitor: Assessing the evidence supporting the role of social enterprise in health and social care. Public Management Review, 20(12), 1790-1814.

Chan, A. (2016). Personal wellbeing of participants of social purpose enterprises: The influence of social support. VOLUNTAS: International Journal of Voluntary and Nonprofit Organizations, 27(4), 1718-1741.

Chan, A., Ryan, S., \& Quarter, J. (2017). Supported social enterprise: A modified social welfare organization. Nonprofit and Voluntary Sector Quarterly, 46(2), 261-279.

Choi, D., Berry, F. S., \& Ghadimi, A. (2020). Policy design and achieving social outcomes: A comparative analysis of social enterprise policy. Public Administration Review, 80(3), 494-505.

De Ruysscher, C., Claes, C., Lee, T., Cui, F., Van Loon, J., De Maeyer, J., \& Schalock, R. (2017). A systems approach to social entrepreneurship. VOLUNTAS: International Journal of Voluntary and Nonprofit Organizations, 28(6), 2530-2545.

Deeming, C. (2013). Addressing the social determinants of subjective wellbeing: The latest challenge for social policy. Journal of Social Policy, 42(3), 541-565.

Defourny, J., \& Nyssens, M. (2012). The EMES approach of social enterprise in a comparative perspective (EMES Working Paper No. 12/03). EMES European Research Network. https://emes. net/publications/working-papers/the-emes-approach-ofsocialenterprise-in-a-comparative-perspective/.

Diochon, M., \& Anderson, A. R. (2009). Social enterprise and effectiveness: A process typology. Social Enterprise Journal, $5(1), 7-29$.

Farmer, J., De Cotta, T., McKinnon, K., Barraket, J., Munoz, S. A., Douglas, H., \& Roy, M. J. (2016). Social enterprise and wellbeing in community life. Social Enterprise Journal, 12(2), 235-254.

Fassio, O., Rollero, C., \& De Piccoli, N. (2013). Health, quality of life and population density: A preliminary study on "contextualized" quality of life. Social Indicators Research, 110(2), 479-488.

Ferguson, K. M. (2007). Implementing a social enterprise intervention with homeless, street-living youths in Los Angeles. Social Work, 52(2), 103-112.

Ferguson, K. M., \& Islam, N. (2008). Conceptualizing outcomes with street-living young adults: Grounded theory approach to evaluating the social enterprise intervention. Qualitative Social Work, $7(2), 217-237$.

Ferguson, K. M., \& Xie, B. (2008). Feasibility study of the social enterprise intervention with homeless youth. Research on Social Work Practice, 18(1), 5-19.

Forsyth, A., Oakes, J. M., Schmitz, K. H., \& Hearst, M. (2007). Does residential density increase walking and other physical activity? Urban Studies, 44(4), 679-697.

Franzini, L., \& Fernandez-Esquer, M. E. (2006). The association of subjective social status and health in low-income Mexican-origin individuals in Texas. Social Science \& Medicine, 63(3), 788-804.

Habibov, N. N., \& Afandi, E. N. (2011). Self-rated health and social capital in transitional countries: Multilevel analysis of comparative surveys in Armenia, Azerbaijan, and Georgia. Social Science \& Medicine, 72(7), 1193-1204.

Hanslmaier, M. (2013). Crime, fear and subjective well-being: How victimization and street crime affect fear and life satisfaction. European Journal of Criminology, 10(5), 515-533.

Haugh, H. (2006). Social enterprise: Beyond economic outcomes and individual returns. In J. Mair, J. Robinson, \& K. Hockerts (Eds.), Social entrepreneurship (pp. 180-205). London: Palgrave Macmillan.

Jang, J., Kim, T. H., Hong, H., Yoo, C. S., \& Park, J. (2018). Statistical estimation of the casual effect of social economy on subjective well-being. VOLUNTAS: International Journal of Voluntary and Nonprofit Organizations, 29(3), 511-525. 
Kelley, J., \& Evans, M. D. (2017). Societal inequality and individual subjective well-being: Results from 68 societies and over 200,000 individuals, 1981-2008. Social Science Research, 62, $1-23$.

Kilpatrick, S., Auckland, S., Johns, S., \& Whelan, J. (2007). Building capacity for rural health: The role of boundary crossers in coalition maturity for partnerships with external agents. In L. Doyle (Ed.), Building stronger communities: Research informing practice. (pp. 220-236). Leicester: NIACE.

Kim, S. (2011). Assessing mobility in an aging society: Personal and built environment factors associated with older people's subjective transportation deficiency in the US. Transportation Research Part F: Traffic Psychology and Behaviour, 14(5), 422-429.

Kim, T. H., \& Moon, M. J. (2017). Using social enterprises for social policy in South Korea: Do funding and management affect social and economic performance? Public Administration and Development, 37(1), 15-27.

Kreft, I. G., De Leeuw, J., \& Aiken, L. S. (1995). The effect of different forms of centering in hierarchical linear models. Multivariate Behavioral Research, 30(1), 1-21.

Macaulay, B., Mazzei, M., Roy, M. J., Teasdale, S., \& Donaldson, C. (2018). Differentiating the effect of social enterprise activities on health. Social Science \& Medicine, 200, 211-217.

Mazzei, M. (2017). Understanding difference: The importance of 'place' in the shaping of local social economies. VOLUNTAS: International Journal of Voluntary and Nonprofit Organizations, 28(6), 2763-2784.

Mendell, M. (2010). Reflections on the evolving landscape of social enterprise in North America. Policy and Society, 29(3), 243-256.

Meng, T., \& Chen, H. (2014). A multilevel analysis of social capital and self-rated health: Evidence from China. Health \& Place, 27, $38-44$.

Ministry of Health and Welfare. (2016). The standard median income. http://www.129.go.kr/info/info04_view.jsp?n=701. Accessed 12 Mar 2020.

Morais-da-Silva, R. L., Segatto, A. P., \& Bezerra-de-Sousa, I. G. (2020). Connecting two sides: A qualitative study on social innovation ventures and poor communities in an emerging economy. VOLUNTAS: International Journal of Voluntary and Nonprofit Organizations, 31, 966-980.

Munoz, S. A., Farmer, J., Winterton, R., \& Barraket, J. O. (2015). The social enterprise as a space of well-being: An exploratory case study. Social Enterprise Journal, 11(3), 281-302.

Murayama, H., Fujiwara, Y., \& Kwachi, I. (2012). Social capital and health: A review of prospective multilevel studies. Journal of Epidemiology, 22(3), 179-197.

Nussbaum, M. (2000). Women and Human Development: The capabilities approach. Cambridge University Press.

Prahalad, C. K. (2005). The fortune at the bottom of the pyramid: Eradicating poverty through profits. Wharton School Publishing.

Rathmann, K., Ottova, V., Hurrelmann, K., de Looze, M., Levin, K., Molcho, M., \& Richter, M. (2015). Macro-level determinants of young people's subjective health and health inequalities: A multilevel analysis in 27 welfare states. Maturitas, 80(4), 414-420.

Richter, A. W., West, M. A., Van Dick, R., \& Dawson, J. F. (2006). Boundary spanners' identification, intergroup contact, and effective intergroup relations. Academy of Management Journal, 49(6), 1252-1269.
Roy, M. J., Donaldson, C., Baker, R., \& Kay, A. (2013). Social enterprise: New pathways to health and well-being? Journal of Public Health Policy, 34(1), 55-68.

Roy, M. J., Donaldson, C., Baker, R., \& Kerr, S. (2014). The potential of social enterprise to enhance health and well-being: A model and systematic review. Social Science \& Medicine, 123, 182-193.

Roy, M. J., \& Hackett, M. T. (2017). Polanyi's 'substantive approach' to the economy in action? Conceptualising social enterprise as a public health 'intervention.' Review of Social Economy, 75(2), 89-111.

Seelos, C., \& Mair, J. (2005). Social entrepreneurship: Creating new business models to serve the poor. Business Horizons, 48(3), 241-246.

Sen, A. (1992). Inequality reexamined. Clarendon Press.

Shaw, E., \& Carter, S. (2007). Social entrepreneurship. Journal of Small Business and Enterprise Development, 14(3), 418-434.

Spicker, P. (2012). Why refer to poverty as a proportion of median income? Journal of Poverty and Social Justice, 20(2), 163-175.

Szwarcwald, C. L., Souza-Júnior, P. R. B. D., Esteves, M. A. P., Damacena, G. N., \& Viacava, F. (2005). Socio-demographic determinants of self-rated health in Brazil. Cadernos De Saúde Pública, 21, S54-S64.

Tanekenov, A., Fitzpatrick, S., \& Johnsen, S. (2018). Empowerment, capabilities and homelessness: The limitations of employmentfocused social enterprises in addressing complex needs. Housing, Theory and Society, 35(1), 137-155.

Teasdale, S. (2010). Models of social enterprise in the homelessness field. Social Enterprise Journal, 6(1), 23-34.

Thomson, H., Atkinson, R., Petticrew, M., \& Kearns, A. (2006). Do urban regeneration programmes improve public health and reduce health inequalities? A synthesis of the evidence from UK policy and practice (1980-2004). Journal of Epidemiology \& Community Health, 60(2), 108-115.

Van der Horst, M., \& Coffé, H. (2012). How friendship network characteristics influence subjective well-being. Social Indicators Research, 107(3), 509-529.

Veenhoven, R. (2000). Well-being in the welfare state: Level not higher, distribution not more equitable. Journal of Comparative Policy Analysis: Research and Practice, 2(1), 91-125.

Vickers, I., Lyon, F., Sepulveda, L., \& McMullin, C. (2017). Public service innovation and multiple institutional logics: The case of hybrid social enterprise providers of health and wellbeing. Research Policy, 46(10), 1755-1768.

Viswanathan, M., \& Rosa, J. A. (2007). Product and market development for subsistence marketplaces: Consumption and entrepreneurship beyond literacy and resource barriers. $A d$ vances in International Management, 20(1), 1-17.

Weaver, R. L. (2018). Re-conceptualizing social value: Applying the capability approach in social enterprise research. Journal of Social Entrepreneurship, 9(2), 79-93.

Weidner, K. L., Rosa, J. A., \& Viswanathan, M. (2010). Marketing to subsistence consumers: Lessons from practice. Journal of Business Research, 63(6), 559-569.

Publisher's Note Springer Nature remains neutral with regard to jurisdictional claims in published maps and institutional affiliations. 